\title{
Computational assessment of environmental hazards of nitroaromatic compounds: influence of the type and position of aromatic ring substituents on toxicity
}

\author{
Oleg V. Tinkov ${ }^{1} \cdot$ Luidmila N. Ognichenko $^{2}$ • Victor E. Kuz'min ${ }^{2}$ • \\ Leonid G. Gorb ${ }^{3}$ Anna P. Kosinskaya ${ }^{2,4} \cdot$ Nail N. Muratov ${ }^{5} \cdot$ Eugene N. Muratov $^{6}$. \\ Frances C. Hill $^{7} \cdot$ Jerzy Leszczynski $^{8}$
}

Received: 19 November 2015/ Accepted: 21 November 2015/Published online: 11 December 2015

(c) Springer Science+Business Media New York 2015

\begin{abstract}
This study summarizes the results of our recent QSAR and QSPR investigations on prediction of numerous aspects of environmental behavior of nitro compounds. In this study, we applied the QSAR/QSPR models previously developed by our group for virtual screening of energetic compounds, their precursors and other compounds containing nitro groups. To make predictions on the environmental impact of nitro compounds, we analyzed the trends in the change of the experimentally obtained and QSAR/ QSPR-predicted values of aqueous solubility, lipophilicity,
\end{abstract}

Electronic supplementary material The online version of this article (doi:10.1007/s11224-015-0715-4) contains supplementary material, which is available to authorized users.

Jerzy Leszczynski

jerzy@icnanotox.org

1 Department of Chemistry, T.G. Shevchenko State University, 3300 Tiraspol, Moldova

2 Department of Molecular Structures and Chemoinformatics, A.V. Bogatsky Physical-Chemical Institute NAS of Ukraine, Odessa 65080, Ukraine

3 HX5, LLC, Vicksburg, MS 39180, USA

4 Odessa National Medical University, 2, Valikhovskiy Lane, Odessa 65026, Ukraine

5 Chemical-Technological Department, Odessa National Polytechnic University, Odessa 65000, Ukraine

6 Laboratory for Molecular Modeling, Division of Chemical Biology and Medicinal Chemistry, Eshelman School of Pharmacy, University of North Carolina, Chapel Hill, NC 27599, USA

7 US Army Research and Development Center, 3909 Halls Ferry Rd., Vicksburg, MS 39180, USA

8 Department of Civil and Environmental Engineering, Interdisciplinary Nanotoxicity Center, Jackson State University, Jackson, MS 39217, USA
Ames mutagenicity, bioavailability, blood-brain barrier penetration, aquatic toxicity on T. pyriformis and acute oral toxicity on rats as a function of chemical structure of nitro compounds. All the models were developed using simplex descriptors in combination with random forest (RF) modeling techniques. We interpreted the possible environmental impact (different toxicological properties) in terms of dividing considered nitro compounds based on hydrophobic and hydrophilic characteristics and in terms of the influence of their molecular fragments that promote and interfere with toxicity. In particular, we found that, in general, the presence of amide or tertiary amine groups leads to an increase in toxicity. Also, it was predicted that compounds containing a $\mathrm{NO}_{2}$ group in the para-position of a benzene ring are more toxic than meta-isomers, which, in turn, are more toxic than ortho-isomers. In general, we concluded that hydrophobic nitroaromatic compounds, especially the ones with electron-accepting substituents, halogens and amino groups, are the most environmentally hazardous.

Keywords Nitroaromatic xenobiotics - Acute toxicity · SiRMS · Virtual screening

In commemoration of Dr. Oleg Shishkin, an outstanding scientist, beloved colleague and good friend.

\section{Introduction}

Toxic environmental chemicals may impact the environment and human health, and therefore, they may pose a considerable risk to society. Unfortunately, the number of chemical compounds with measured physical-chemical 
properties and toxicity is just a small fraction of the chemical compounds of environmental concern. In the 1990s, the US Environmental Protection Agency, Office of Toxic Substances (OTS), listed approximately 70,000 industrial chemicals. About 1000 chemicals have been added each year. However, even simple toxicological experiments for such compounds have been carried out very rarely.

Even for the case where experimental protocols for toxicity testing have been established and the cost of testing of an individual compound has been reduced significantly, toxicity measurements are still quite costly and time-consuming. This is the key reason why computational chemical toxicology continues to be a viable approach to reduce the amount of efforts and cost of experimental toxicity assessments [1]. Tighter controls on the nature and scope of animal testing used to determine toxicity have pointed to computational modeling approaches as a good alternative to experimental testing. Ongoing improvements in computational approaches should result in significant cost savings that could be achieved, if the potential property of a new chemical could be predicted before its synthesis and biological testing. To address this challenge, many quantitative structure-activity relationship (QSAR) studies have been conducted and reported for different toxicity endpoints.

Nitroaromatic compounds are widely used in medicine, industry and agriculture. Nitroaromatic pesticides as well as explosive residues are considered to be toxic environmental contaminants. Some of these compounds have mutagenic or carcinogenic activity and may bioaccumulate and propagate through the food chain. Therefore, the presence of aromatic and nitroaromatic xenobiotics in the environment may create serious public health and environmental problems, and both the nature and degree of aromatic substitutions may have profound effects on the toxicity of nitroaromatic compounds [2].

A prerequisite for correct predictive assessment of chemical toxicity using QSAR is the accurate assignment of toxic action modes that could be caused by different factors related to the structure of molecules-toxicants in a complex manner. The two best known chemical mechanisms of nitro compound toxic action are one- and twoelectron reduction [3]. The one-electron reduction is accompanied by formation of highlyreactive particles (free radicals), e.g., $\mathrm{O} 2-$ and $\mathrm{OH}$. These species cause the oxidative stress of living cells and oxidation of lipids [3]. Two-electron reduction of nitroaromatics is accompanied by creation of corresponding nitroso compounds and hydroxylamines. These compounds form adducts to proteins and DNA that block normal functioning of the latter [3]. In addition, nitroaromatics participate in SNAr reactions with nucleophilic sites in peptides and DNA (i.e.,
$-\mathrm{OH},-\mathrm{SH}$ and $-\mathrm{NH} 2$ groups), forming complexes with electron-donating heterocycles of peptides and DNA, which interfere with their functions [4] and act as uncoupling agents in oxidative phosphorylation [5].

In other words, the nitroaromatics display complex mechanisms of toxicity, and numerous QSAR studies have been carried out to explain and predict toxicity of nitro compounds on different living systems [6-9]. In a paper [10], the QSAR analysis of oral toxicity on rats has been extended to 28 selected nitroaromatic molecules. In spite of acceptable QSAR models being developed on the basis of topological and quantum-chemical indexes, a lot of questions remain unanswered. One of them, addressed in this paper in great detail, is the relationship between chemical structure and toxicity.

In a recent paper [11], QSAR models are presented for the estimation of the toxicity of 28 nitroaromatic compounds including some well-known explosives. This work was conducted using the principal component analysis (PCA) method, the multiple linear regression method (MLR), the multiple nonlinear regressions (MNLR) and the artificial neural network (ANN). The predicted results of various nitroaromatic compounds afford reliable prediction of $\mathrm{LD}_{50}$ with respect to experimental data. Density functional theory (DFT) calculations have been carried out in order to get insights into the structure, chemical reactivity and property information for the series of study compounds.

Ecological safety of chemical compounds is not determined by a single property, but by a complex of different properties. Along with the many forms toxicity can take, physical processes such as permeability to and accumulation in different bio- and eco-environments also play an important role. The latter properties are mostly determined by aqueous solubility and lipophilicity of toxicants. Thus, the goal of our study is to estimate the ecological safety of the most widely used nitroaromatic compounds by virtual screening of their physical-chemical properties and toxicity. We also have studied the influence of donor and acceptor type of s substituents and the influence of their position in aromatic ring on the observed value of toxicity.

\section{Computational methods}

All the models were built using simplex representation of molecular structure (SiRMS) [12, 13] descriptors and random forest (RF) [14-16] modeling techniques.

The main concept of SiRMS approach is that any molecule can be represented as a system of different simplexes (tetratomic fragments with fixed composition and topological structure). At the 2D level, the connectivity of atoms in simplex, atom type and bond nature (single, 
double, triple and aromatic) are taken into consideration. The only descriptors used in this study were counts of different types of connected 2D simplexes. Atoms were differentiated not only by their atom types but also by other physico-chemical characteristics, such as partial charge, lipophilicity, refraction and the ability for an atom to be a hydrogen bond donor or acceptor. The usage of sundry variants of differentiation of simplex vertexes (atoms) represents the principal feature of the proposed approach. The main advantages of SiRMS are the possibility of analysis of molecules with noticeable structural differences as well as the possibility to reveal individual molecular fragments (simplex combinations) promoting or interfering with investigated property. This information could provide for the formation of new hypotheses as to mechanisms of chemical toxic action and allows to carry out the molecular design. SiRMS approach avoids additive contributions of structural fragments, because the contributions of atom/or structural fragment depend on their surroundings. SiRMS methodology does not have many of the restrictions of such well-known and widely used approaches as CoMFA, CoMSIA and HASL, in which the application is limited to a structurally homogeneous set of molecules only. SiRMS approach is similar to HQSPR approach and does not have its limitations (consideration of atom type only) and deficiencies (an ambiguity of descriptor formation during the hashing of molecular holograms).

\section{Results and discussion}

In this study, we continue the investigation of ecological safety of nitroaromatic compounds. We use QSAR/QSPR models developed previously by our group [6-24] for virtual screening of energetic compounds including such explosives as RDX, HMX and their precursors to predict their aquatic toxicity on $T$. pyriformis, acute oral toxicity on rats, aqueous solubility, lipophilicity, Ames mutagenicity, bioavailability and blood-brain barrier penetration. Membership of a given chemical to a model's applicability domain (AD) was estimated in every case. Statistical characteristics of developed models and references to original publication are presented in Table 1.

A dataset of nitro compounds considered in this study was divided into two groups of compounds: (1) hydrophobic $(\log \mathrm{P} \geq 3)$ and almost non-soluble $(\log \mathrm{Sw} \leq$ $-3)$ and (2) hydrophilic $(\log \mathrm{P} \leq 2)$ and relatively highly soluble $(\log \mathrm{Sw} \geq-2)$ (group I and group II, relatively). To assign a compound to one of these groups, we used experimental lipophilicity and solubility values; if these data were unknown, we used the values predicted by our models developed earlier $[17,20]$. Obviously, these two groups of compounds have different mechanisms of penetration into biological environment; however, compounds belonging to both groups may be harmful to living organisms. In total, 13 compounds belong to group 1 and 39 to group 2. The distribution of all investigated compounds between these groups is represented in Supplementary Table S1, and the most toxic compounds belonging to groups I and II are listed in Table 2. For instance, $\quad N$-(cyclopropylmethyl)-2,6-dinitro- $N$-propyl-4(trifluoromethyl)aniline $\left(\operatorname{lgLD}_{50}=-2.04\right)$ and $N$-(2chloroethyl)-2,6-dinitro- $N$-propyl-4-(trifluoromethyl)aniline $\left(\operatorname{lgL} D_{50}=-2.08\right)$ belong to group I, and 3,5-dinitrobenzamide $\left(\operatorname{lgLD}_{50}=-2.23\right)$ and 4-nitrobenzamide $\left(\operatorname{lgLD}_{50}=-2.54\right)$ belong to group II. As obvious from Table 2, both groups contain compounds with high acute toxicity $\left(\operatorname{lgL} D_{50}<2\right)$. All mentioned compounds are toxic to Tetrahymena Pyriphormis, are mutagenic and possess high bioavailability. Hydrophobic, non-soluble compounds are generally more active neurotoxicants because, unlike hydrophilic soluble nitroaromatics from

Table 1 Statistical characteristics of QSAR models used for virtual screening

\begin{tabular}{|c|c|c|c|c|c|c|c|}
\hline Property & Endpoint & $\begin{array}{l}\text { Training } \\
\text { set }\end{array}$ & $\begin{array}{l}\text { External test } \\
\text { set }\end{array}$ & $R_{\mathrm{oob}}^{2}$ & $R_{\text {ext_test }}^{2}$ & $\begin{array}{l}\text { Risk estimate } \\
\text { (oob) }\end{array}$ & References \\
\hline Lipophilicity & $\log P$ & 10973 & - & 0.93 & - & - & [11] \\
\hline Mutagenity & Class* & 4361 & - & - & - & 0.18 & {$[12]$} \\
\hline $\begin{array}{l}\text { Aquatic toxicity tested on Tetrahymena } \\
\text { pyriformis }\end{array}$ & $\operatorname{Lg}\left(\operatorname{IGC}_{50}^{-1}\right)$ & 644 & 449 & 0.81 & 0.83 & - & {$[5]$} \\
\hline Bioavailbility & Fclass_70 \%* & 628 & - & - & - & 0.27 & {$[13]$} \\
\hline Bioavailability & Fclass_80 \%* & 628 & - & - & - & 0.24 & {$[13]$} \\
\hline Bioavailability & Fclass_90 \%* & 628 & - & - & - & 0.21 & {$[13]$} \\
\hline Solubility & $\operatorname{LogSw}$ & 1272 & - & 0.91 & - & - & [9] \\
\hline Blood-brain barrier penetration & $\operatorname{LogBB}$ & 325 & - & 0.65 & - & - & {$[14-16]$} \\
\hline Acute toxicity tested on rats & $\operatorname{LgLD}_{50}$ & 858 & 214 & 0.53 & 0.55 & - & [17] \\
\hline
\end{tabular}

* Classification model; Fclass_70 \%, Fclass_80 \%, Fclass_90 \% —borders of class 
Table 2 Investigated properties of nitroaromatic toxicants

\begin{tabular}{|c|c|c|c|c|c|c|c|c|c|c|c|}
\hline \multirow[b]{2}{*}{ ID* } & \multirow[b]{2}{*}{ Name } & \multicolumn{2}{|c|}{$\begin{array}{l}\text { Lipophilicity } \\
\text { LogP }\end{array}$} & \multirow[t]{2}{*}{$\begin{array}{l}\text { Ames } \\
\text { test }\end{array}$} & \multirow{2}{*}{$\begin{array}{l}\text { Toxicity to } \\
\text { tetrahimena, } \\
\text { LgIGC }_{50}^{-1} \\
\text { Toxicity }\end{array}$} & \multicolumn{2}{|c|}{ Bioavailability } & \multirow[t]{2}{*}{$\begin{array}{l}\text { Water } \\
\text { solubility }\end{array}$} & \multirow[t]{2}{*}{$\begin{array}{l}\text { GEB } \\
\operatorname{logBBB}\end{array}$} & \multicolumn{2}{|c|}{$\begin{array}{l}\text { Acute toxicity } \\
\text { to rats, } \\
\operatorname{LgLD}_{50}\end{array}$} \\
\hline & & Obs. & Calc. & & & $70 \%$ & $80 \%$ & & & Obs. & Calc. \\
\hline \multicolumn{12}{|c|}{ Group I } \\
\hline 27 & $\begin{array}{l}N \text {-(cyclopropylmethyl)-2,6-dinitro- } N \text { - } \\
\text { propyl-4-(trifluoromethyl)aniline }\end{array}$ & 5.54 & 5.22 & 1 & 1.13 & 1 & 1 & -5.16 & 0.33 & -2.04 & -2.29 \\
\hline 29 & $\begin{array}{l}N \text {-(2-chloroethyl)-2,6-dinitro- } N \text {-propyl- } \\
\text { 4-(trifluoromethyl)aniline }\end{array}$ & 4.63 & 4.73 & 1 & 0.76 & 1 & 1 & -4.94 & 0.50 & -2.08 & -2.52 \\
\hline 25 & $\begin{array}{l}\text { O-ethyl O-4-nitrophenyl } \\
\text { phenylphosphonothioate }\end{array}$ & 3.85 & 3.79 & 1 & 1.49 & 1 & 1 & -4.09 & 0.02 & -4.67 & -3.58 \\
\hline 24 & $\begin{array}{l}\text { 2,6-Dinitro- } N \text {-propyl-4- } \\
\text { (trifluoromethyl)aniline }\end{array}$ & 3.65 & 3.63 & 1 & 0.62 & 1 & 1 & -4.17 & 0.17 & & -2.29 \\
\hline & Group II & & & & & & & & & & \\
\hline 88 & 2-Hydroxylamino-4,6-dinitrotoluene & & 1.86 & 1 & 0.75 & 1 & 0 & -2.00 & -0.09 & & -3.04 \\
\hline 12 & 3,5-Dinitrobenzamide & 0.83 & 0.64 & 1 & 0.44 & 1 & 0 & -2.00 & -0.24 & -2.23 & -2.59 \\
\hline 20 & 3-Nitrobenzamide & 0.77 & 0.63 & 1 & 0.15 & 1 & 1 & -1.92 & -0.19 & & -2.06 \\
\hline 19 & 4-Nitrobenzamide & 0.82 & 0.63 & 1 & 0.15 & 1 & 1 & -1.97 & -0.19 & -2.54 & -2.11 \\
\hline 16 & 2-Nitrobenzamide & -0.15 & 0.52 & 1 & 0.21 & 1 & 1 & -1.93 & -0.24 & & -1.97 \\
\hline
\end{tabular}

* This ID corresponds to ID from Supplemental Table S1 containing data about the whole dataset

Table 3 Influence of molecular fragments on acute toxicity, lipophilicity and water solubility

\begin{tabular}{|c|c|c|c|c|c|c|}
\hline \multirow[t]{2}{*}{ Property } & \multicolumn{6}{|l|}{ Fragments } \\
\hline & $\mathrm{a}$ & $\mathrm{b}$ & $\mathrm{c}$ & $\mathrm{d}$ & $\mathrm{e}$ & $\mathrm{f}$ \\
\hline Toxicity & $-0.78(-0.90 ;-0.69)$ & $-1.76(-2.12 ;-1.52)$ & -0.49 & -0.92 & -0.99 & -1.18 \\
\hline Lipophilicity & $0.20(0.14 ; 0.36)$ & $1.32(0.94 ; 2.05)$ & 0.99 & 1.18 & 0.58 & 1.71 \\
\hline Solubility & $-0.59(-0.94 ;-0.27)$ & $-1.64(-2.5 ;-0.76)$ & -0.70 & 0.96 & -1.66 & -0.97 \\
\hline Toxicity & $b>f>e>d>c>a$ & & & & & \\
\hline Lipophilicity & $f>b>d>c>e>a$ & & & & & \\
\hline Solubility & $d>a>c>f>b>e$ & & & & & \\
\hline
\end{tabular}

group II, group I compounds have much better bloodbrain barrier permeability.

One may obtain a deeper understanding of influences of molecular structure on toxicity by considering the influence of molecular fragments on the observed and predicted toxicity. The results of comparative analysis of molecular fragment contributions to acute toxicity, lipophilicity and aqueous solubility derived from developed models are shown in Table 3. As is shown in the table, the presence of amide or tertiary amine groups leads to an increase in toxicity. There is also some symbiosis between the influence of fragments $\mathrm{a}-\mathrm{f}$ on toxicity and lipophilicity (Spearman's $r=0.77)$. Most likely, a toxicants' ability to penetrate through lipophilic membranes during their intake in organs and tissues is one of the main factors promoting acute toxicity. Also, the higher the lipophilicity of a compound, the smaller its excretion from the organism.

We have also analyzed the influence of electron-donating and electron-accepting substituents on acute toxicity taking into account their relative position toward the nitro group in aromatic ring. To address this question, we designed a set of substituted mono-, di- and trinitrobenzenes and predicted their acute toxicity by the corresponding QSAR models (see Figs. 1 and 2). Analyzing data presented in Figs. 1 and 2, we concluded that toxicity of nitroaromatics is a complex phenomenon, influenced by 
Fig. 1 Toxicity change for isomers of monosubstituted: a nitrobenzene;

b dinitrobenzene;

c trinitrobenzene
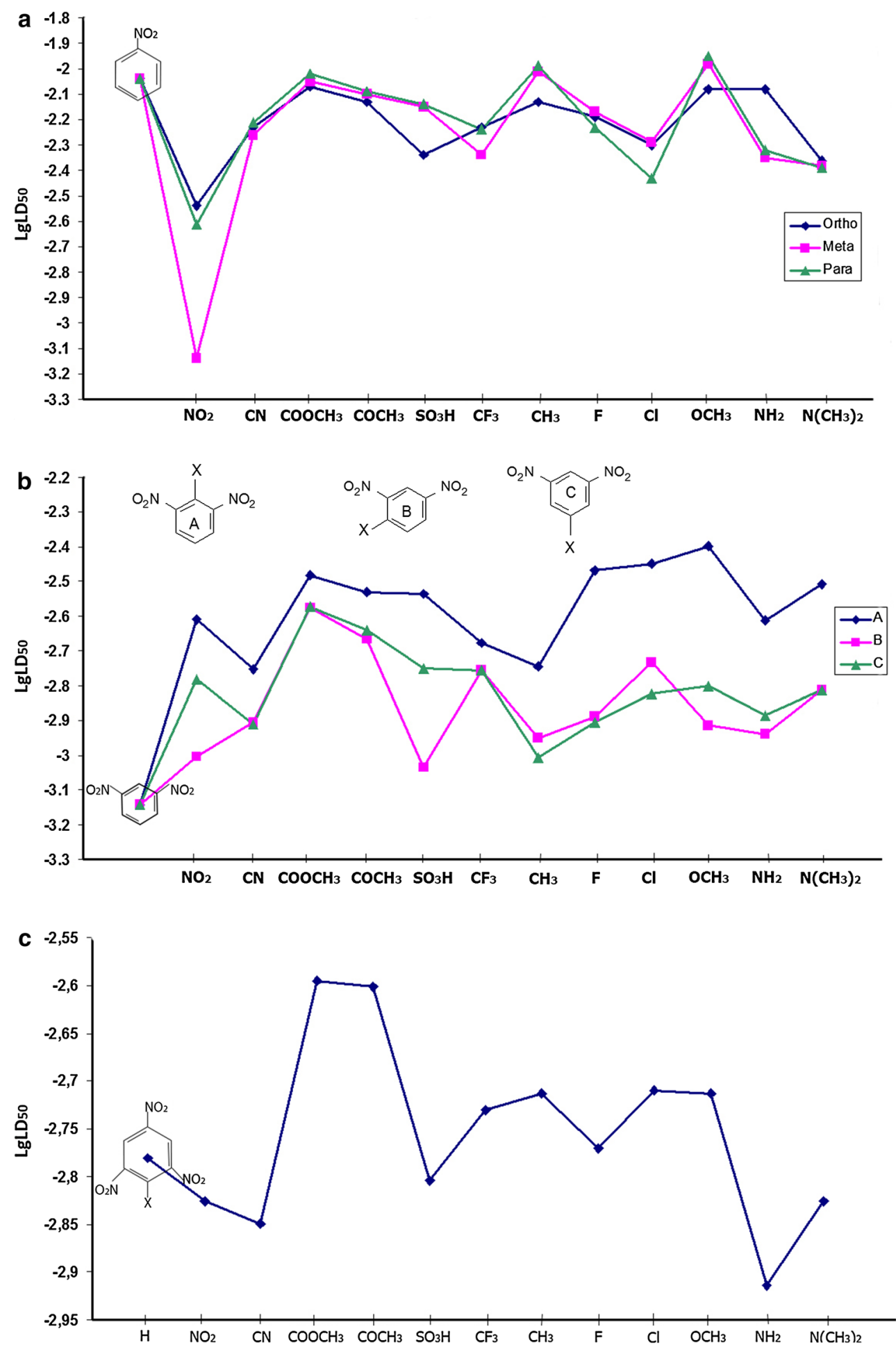

many processes at molecular level, which is realized through different mechanisms, and as one could see from Fig. 1, there are no constant trends of the influence of electron effects of substituents on toxicity. Meta-isomer of dinitrobenzene is the most toxic among the compounds (see Fig. 1a). According to our models, the rest of nitrobenzene derivatives with electron-accepting substituents and nitrobenzenes with electron-donating groups, i.e., halogens and amines, have comparable toxicity. Nitrotoluene and methoxynitrobenzene have somewhat lower toxicity. Meta-isomers possess higher toxicity than ortho- and para-isomers only for the most toxic derivatives 

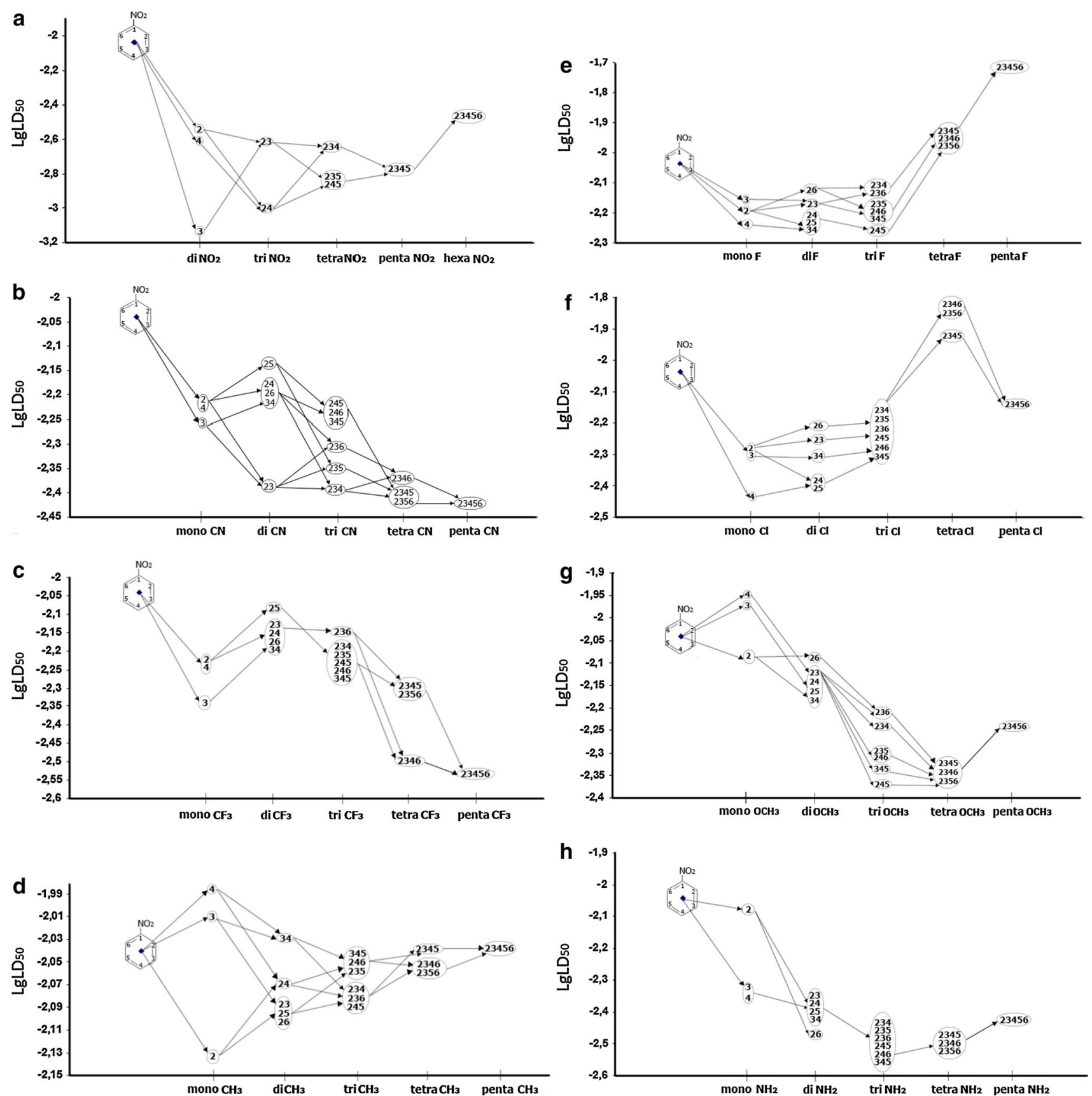

Fig. 2 Evolution of toxicity change for nitro- (a), cyano- (b), trifluoromethyl- (c), methyl- (d), fluoro- (e), chloro- (f), methoxy- (g) and amino (h) of substituted mononitrobenzenes. Numbers in circles correspond to the positions of substituents in benzene ring

of nitrobenzene with $-\mathrm{NO}_{2},-\mathrm{CN},-\mathrm{CF}_{3}$ and $-\mathrm{NH}_{2}$ substituents; for all other compounds, ortho- or para-isomers are more toxic. It is evident from Fig. 1b that dinitrobenzenes are more toxic than their substituted derivatives. In all cases, A-isomers (see designation in Fig. 1b) have lower toxicity. For substituted dinitrobenzenes (Fig. 1b), one could observe that, in general, B-isomers are more toxic than C-isomers. Nitro-, sulfonic- and methoxy-substituted dinitrobenzenes have the biggest difference in toxicity between the isomers. Insertion of nitro, cyano, sulfonic or primary amine in 1,3,5-trinitrobenzene increases toxicity (Fig. 1c).

Also, we have made a more detailed investigation of mono- to penta-substituted mononitrobenzenes. "Evolution" of toxicity variation for $-\mathrm{NO}_{2},-\mathrm{CN},-\mathrm{CF}_{3},-\mathrm{CH}_{3},-\mathrm{F}$, $-\mathrm{Cl},-\mathrm{OCH}_{3}$ and $-\mathrm{NH}_{2}$ derivatives is represented in Fig. 2. There are no simple trends for the influence of isomerism on the toxicity of mononitrobenzene derivatives. The 
largest toxicity changes are observed for mononitro, dicyano, tetratrifluoromethyl, monomethyl, trifluoro, dichloro, monomethoxy and mono-primary amine derivatives of nitrobenzene. An addition of five $-\mathrm{CN},-\mathrm{CF}_{3},-\mathrm{Cl}$ $-\mathrm{OCH}_{3},-\mathrm{NH}_{2}$ and $-\mathrm{NO}_{2}$ groups leads to an increase in toxicity. However, an addition of five $-\mathrm{F}$ groups decreases toxicity.

Thus, in most cases nitro and cyano fragments are "toxicophores" for different substituted nitrobenzenes High toxicity of these fragments is confirmed by the previous studies [25]. For example, 2,4-dinitrophenol and cyanide are inhibitors of oxidative phosphorylation [26, 27]. The cyanide anion is an inhibitor of the enzyme $c y$ tochrome c oxidase in the fourth complex of the electron transport chain. The binding of cyanide to this enzyme prevents transport of electrons from cytochrome $c$ to oxygen. As a result, the electron transport chain is disrupted, meaning that the cell can no longer aerobically produce ATP for energy.

\section{Conclusions}

We have used the models based on simplex representation of molecular structure (SiRMS) descriptors for computational assessment of environmental hazards of nitroaromatic compounds. Molecular fragments that promote and interfere with toxicity were defined on the basis of the developed models. In particular, it was found that in most cases, amide, tertiary amine, nitro and cyano groups lead to increase in toxicity. Summarizing our results, we would like to note that hydrophobic nitroaromatic compounds, especially the ones with electron-accepting substituents, halogens and amino groups, are the most environmentally hazardous. The obtained results should be verified by experimental study in order to provide feedback on the accuracy of the proposed new technique. As future directions, we plan to create computational expert system based on QSAR/QSPR models described here for the prediction of environmental toxicity of nitroaromatics and related compounds.

Acknowledgments We thank ERDC for financial support (grant number W912HZ-13-P-0037). The computation time was provided by the Extreme Science and Engineering Discovery Environment (XSEDE) by National Science Foundation Grant Number OCI1053575 and XSEDE award allocation Number DMR110088 and by the Mississippi Center for Supercomputer Research. EM is grateful for financial support from the US National Institutes of Health (GM 096967 and GM66940). The use of trade, product or firm names in this report is for descriptive purposes only and does not imply endorsement by the US Government. Results in this study were funded and obtained from research conducted under the Environmental Quality Technology Program of the United States Army Corps of Engineers by the US Army ERDC. Permission was granted by the
Chief of Engineers to publish this information. The findings of this report are not to be construed as an official Department of the Army position unless so designated by other authorized documents.

\section{References}

1. Zhu H, Tropsha A, Fourches D, Varnek A, Papa E, Gramatica P, Oberg T, Dao P, Cherkasov A, Tetko IV (2008) Combinatorial QSAR modeling of chemical toxicants tested against Tetrahymena pyriformis. J Chem Inf Model 48:766-784

2. Donlon BA, Razo-Flores E, Field JA, Lettinga G (1995) Toxicity of $\mathrm{N}$-substituted aromatics to acetoclastic methanogenic activity in granular sludge. Appl Environ Microbiol 61:3889-3893

3. Nemeikaitè-Čènienè A, Miliukienė V, Šarlauskas V, Maldutis E, Čenas N (2006) Chemical aspects of cytotoxicity of nitroaromatic explosives: a review. Chemija 17:34-41

4. Kuz'min VE, Artemenko AG, Kovdienko NA, Tetko IV, Livingstone DJ (2000) Lattice model for QSAR studies. J Mol Model 6:517-526

5. Donlon BA, Razo-Flores E, Field JA, Lettinga G (1995) Toxicity of $\mathrm{N}$-substituted aromatics to acetoclastic methanogenic activity in granular sludge. Appl Environ Microbiol 61:3889-3893

6. Agrawal WK, Khadikar PV (2001) QSAR prediction of toxicity of nitrobenzenes. Bioorg Med Chem 9:3035-3040

7. Cronin MTD, Schultz TW (2001) Development of quantitative structure-activity relationships for the toxicity of aromatic compounds to Tetrahymena pyriformis: comparative assessment of the methodologies. Chem Res Toxicol 14:1284-1295

8. Pouretedal HR, Keshavarz MH (2011) Prediction of toxicity of nitroaromatic compounds through their molecular structures. J Iran Chem Soc 8(1):78-89

9. Ayyapan G (2013) Chemo Informatics QSAR analysis of nitroaromatic compounds toxicity. Int $J$ Innov Res Sci En Technol 2(2):372-375

10. Isayev O, Rasulev B, Gorb L, Leszczynski J (2006) Structuretoxicity relationships of nitroaromatic compounds. Mol Divers 10:233-245

11. Elidrissi B, Ousaa A, Ghamalia M, Chtitaa S, Ajanaa MA, Bouachrineb M, Lakhlifia T (2014) Toxicity in vivo of nitroaromatic compounds: DFT and QSAR results. J Comput Aided Mol Des 4(3):28-37

12. Kuz'min VE, Artemenko AG, Muratov EN (2008) Hierarchical QSAR technology based on the simplex representation of molecular structure. J Comput Aided Mol Des 22:403-421

13. Muratov EN, Artemenko AG, Kuz'min AG, Lozitsky VE, Fedchuk VP, Lozytska AS, Boschenko RN, Gridina YA (2005) Investigation of anti-influenza activity using hierarchic QSAR technology on the base of simplex representation of molecular structure. Antiv Res 65:A62-A63

14. Polishchuk PG, Muratov EN, Artemenko AG, Kolumbin OG, Muratov NN, Kuz'min VE (2009) Application of random forest approach to QSAR prediction of aquatic toxicity. J Chem Inf Model 49:2481-2488

15. Kuz'min VE, Muratov EN, Artemenko AG, Gorb L, Qasim M, Leszczynski J (2008) The effect of nitroaromatics' composition on their toxicity in vivo: novel, efficient non-additive 1D QSAR analysis. Chemosphere 72:1373-1380

16. Kuz'min VE, Muratov EN, Artemenko AG, Gorb L, Qasim M, Leszczynski J (2008) The effects of characteristics of substituents on toxicity of the nitroaromatics: HiT QSAR study. J Comput Aided Mol Des 22:747-759

17. Muratov EN, Kuz'min VE VE, Artemenko AG, Kovdienko NA, Gorb L, Hill F, Leszczynski J (2010) New QSPR equations for 
prediction of aqueous solubility for military compounds. Chemosphere 79:887-890

18. Kovdienko NA, Polishchuk PG, Muratov EN, Artemenko AG, Kuz'min VE, Gorb L, Hill F, Leszczynski J (2010) Application of random forest and multiple linear regression techniques to QSPR prediction of an aqueous solubility for military compounds. Mol Inform 29:394-406

19. Fourches D, Muratov EN, Tropsha A (2010) Trust, but verify: on the importance of chemical structure curation in cheminformatics and QSAR modeling research. J Chem Inf Model 50:1189-1204

20. Ognichenko LN, Kuz'min VE, Gorb L, Hill F, Artemenko AG, Polischuk PG, Leszczynski J (2012) QSPR prediction of lipophilicity for organic compounds using random forest technique on the basis of simplex representation of molecular structure. Mol Inform 31:273-280

21. Sushko Iu, Novotarskyi S, Korner R, Pandey AK et al (2010) Applicability domains for classification problems: benchmarking of distance to models for ames mutagenicity set. J Chem Inf Model 50:2094-2111
22. Golovenko NYA, Kuz'min VE, Artemenko AG et al (2011) Prediction of bioavailability of drugs by the method of classification models. J Klin Inform Telemed 7:88-92

23. Kosinskaya AP, Ognichenko LN, Polishchuk PG, Kuz'min VE (2014) Structural and functional interpretation of 2D QSAR models of structure-blood-brain barrier permeability relationship of organic compounds. In: Abstracts of the 20th international conference on EuroQSAR (understanding chemical-biological interactions). St-Petersburg, Russia, 31 Aug-Sep 4, 2014, p 147

24. Tinkov OV, Polishchuk PG, Artemenko AG, Kuz'min VE (2012) The investigation of acute toxicity and physical-chemical properties of organic compounds. J Sib Fed Univ 5:95-104

25. Li X, Chen L, Cheng F et al (2014) In silico prediction of chemical acute oral toxicity using multi-classification methods. J Chem Inf Model 54:1061-1069

26. Heytler PG (1979) Uncouplers of oxidative phosphorylation. Methods Enzymol 55:442-462

27. Nelson DL, Cox MM (2000) Lehniger principles of biochemistry. Worth Publishers, New York 